\title{
Correction to: Certolizumab Pegol in the Treatment of Psoriasis and Psoriatic Arthritis: Preliminary Real- Life Data
}

Annunziata Dattola · Maria Vittoria Cannizzaro · Mauro Mazzeo ·

Luca Bianchi

Published online: November 25, 2017

(c) The Author(s) 2017. This article is an open access publication

\section{Correction to: Dermatol Ther (Heidelb) \\ https://doi.org/10.1007/s13555- \\ 017-0208-z}

In the original publication, part Fig. $3 \mathrm{~b}$ and $\mathrm{c}$ were interchanged. The correct versions are given below.

Open Access. This article is distributed under the terms of the Creative Commons Attribution-NonCommercial 4.0 International License (http://creativecommons.org/licenses/ by-nc/4.0/), which permits any noncommercial use, distribution, and reproduction in any medium, provided you give appropriate credit to the original author(s) and the source, provide a link to the Creative Commons license, and indicate if changes were made.

The online version of the original article can be found under https://doi.org/10.1007/s13555-017-0208-z.

A. Dattola $(\bowtie) \cdot$ M. V. Cannizzaro - M. Mazzeo .

L. Bianchi

Department of Dermatology, University of Rome

"Tor Vergata", Rome, Italy

e-mail: nancydattola@gmail.com

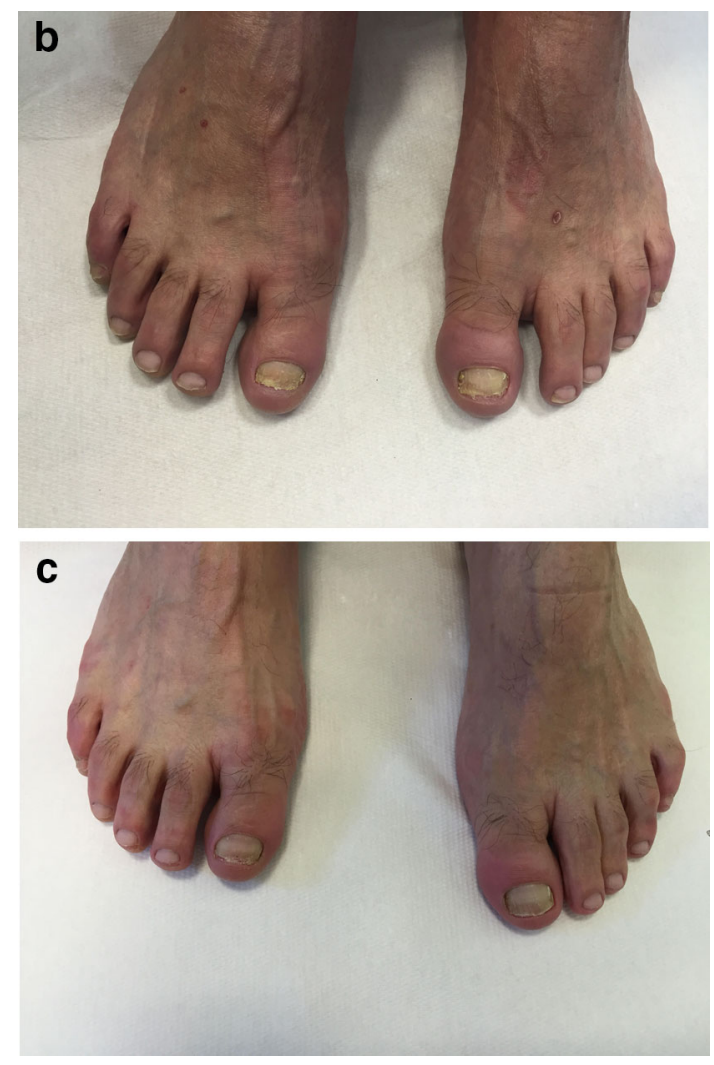

